\title{
Central blood pressure assessment using 24-hour brachial pulse wave analysis
}

This article was published in the following Dove Press journal:

Journal of Vascular Diagnostics

24 October 2014

Number of times this article has been viewed

\author{
Maria Lorenza Muiesan \\ Massimo Salvetti \\ Fabio Bertacchini \\ Claudia Agabiti-Rosei \\ Giulia Maruelli \\ Efrem Colonetti \\ Anna Paini \\ Clinica Medica, Department of \\ Clinical and Experimental Sciences, \\ University of Brescia, Brescia, Italy
}

Correspondence: Maria Lorenza Muiesan, Clinica Medica, Department of Clinical and Experimental Sciences, University of Brescia, 2a Medicina, Spedali Civili di Brescia, Piazza Spedali Civili I, 25100 Brescia, Italy

Tel +39030 396044 ext 3995829

Fax +39030 3384348

Email marialorenza.muiesan@unibs.it

\begin{abstract}
This review describes the use of central blood pressure (BP) measurements during ambulatory monitoring, using noninvasive devices. The principles of measuring central BP by applanation tonometry and by oscillometry are reported, and information on device validation studies is described. The pathophysiological basis for the differences between brachial and aortic pressure is discussed. The currently available methods for central aortic pressure measurement are relatively accurate, and their use has important clinical implications, such as improving diagnostic and prognostic stratification of hypertension and providing a more accurate assessment of the effect of treatment on BP.
\end{abstract}

Keywords: aortic blood pressure measurements, ambulatory monitoring, pulse wave analysis

\section{Introduction}

Since 1898 , blood pressure (BP) has been conventionally measured over the brachial artery by the Riva-Rocci sphygmomanometer. ${ }^{1}$ BP, always measured by sphygmomanometry, has been shown to predict cardiovascular (CV) morbidity and mortality. In more recent years, new devices for automatic BP measurement have become available, both for 24-hour recording and for home self-assessment of BP. These devices have become quite popular for a wider out-of-office BP assessment, but they still give a measure of brachial BP.

About 30 years ago, the potential clinical importance of central aortic BP evaluation was proposed by a group of researchers. ${ }^{2-6}$ Invasive hemodynamic studies have shown that systolic BP (SBP) is considerably different when measured in the brachial artery versus in the aorta, emphasizing the need for central BP recognition. ${ }^{7}$ In addition, there is increasing evidence that central SBP may be a greater predictor of future CV events than brachial pressure. ${ }^{8,9}$ The non-invasive assessment of central aortic BP has become available, and the estimation of central BP by these noninvasive, accurate devices has enabled a better understanding of waveforms and of their changes resulting from the onset of physiological and pathological conditions. ${ }^{10}$

\section{Usefulness of central BP measurements}

Normally, aortic or carotid (central) systolic and pulse pressures are lower than peripheral (brachial) systolic and pulse pressures, while mean and diastolic pressures vary little from the aorta to the brachial artery due to the absence of significant resistance at the level of the large conduit arteries. ${ }^{2}$ The difference in SBP (and pulse) may vary from 1 up to $30 \mathrm{mmHg}$, and different values have been observed among individuals. ${ }^{2}$ 
The phenomenon is due to the pulsatile component of $\mathrm{BP}$, whereas the steady component (usually represented by mean BP) does not change significantly along the arterial tree when the subject is lying down. ${ }^{11}$ The increase of BP from the aorta to the peripheral (brachial or radial) arteries, named the amplification pressure, may be calculated as the ratio of brachial to central pulse pressure, and progressively decreases from young to older subjects (Figure 1). The amplification pressure is a physiological phenomenon, and it depends on hemodynamic and pathophysiological characteristics of each subject. Among all these characteristics, advancing age, reduced heart rate, aortic stiffening (largely influenced by age), reduced body height (reflecting reduced aortic length and volume), female sex (reflecting the impact of a reduced average body height versus male sex), and increased BP are the most important factors that account for a reduction of the difference between central aortic pressure and brachial BP, and for a reduction of the pulse pressure amplification.

For these reasons, it may be difficult to extrapolate central $\mathrm{BP}$ from brachial BP in a single subject, and this aspect may have important clinical implications. The difference between brachial and central pressure is usually greater in younger male subjects, when brachial BP values are elevated; as a consequence, some younger people could be classified as hypertensive despite their central BP being normal or low. In these cases, the classification of normotensive or hypertensive on the basis of brachial BP may not reflect the true risk related to central BP, with the potential risk of over-treatment.

The central aortic pressure reflects the pressure in the large conduit arteries, and is representative of the real hemodynamic stress imposed on the heart, the coronary circulation, the cerebral vessels, and the renal microcirculation. ${ }^{12,13}$ Several studies have addressed this point, and have found a relationship between central aortic systolic or pulse pressure and left ventricular (LV) hypertrophy, concentric geometry of the left ventricle,$^{14}$ extent of coronary atherosclerosis, and intima-media thickness. ${ }^{14-19}$ Very recently, the closer relationship of central BP with retinal abnormalities (wall-to-lumen ratio or retinal arterioles) was reported. ${ }^{20,21}$

However, the real clinical importance of central measures of BP is based on the evidence of a strong prediction
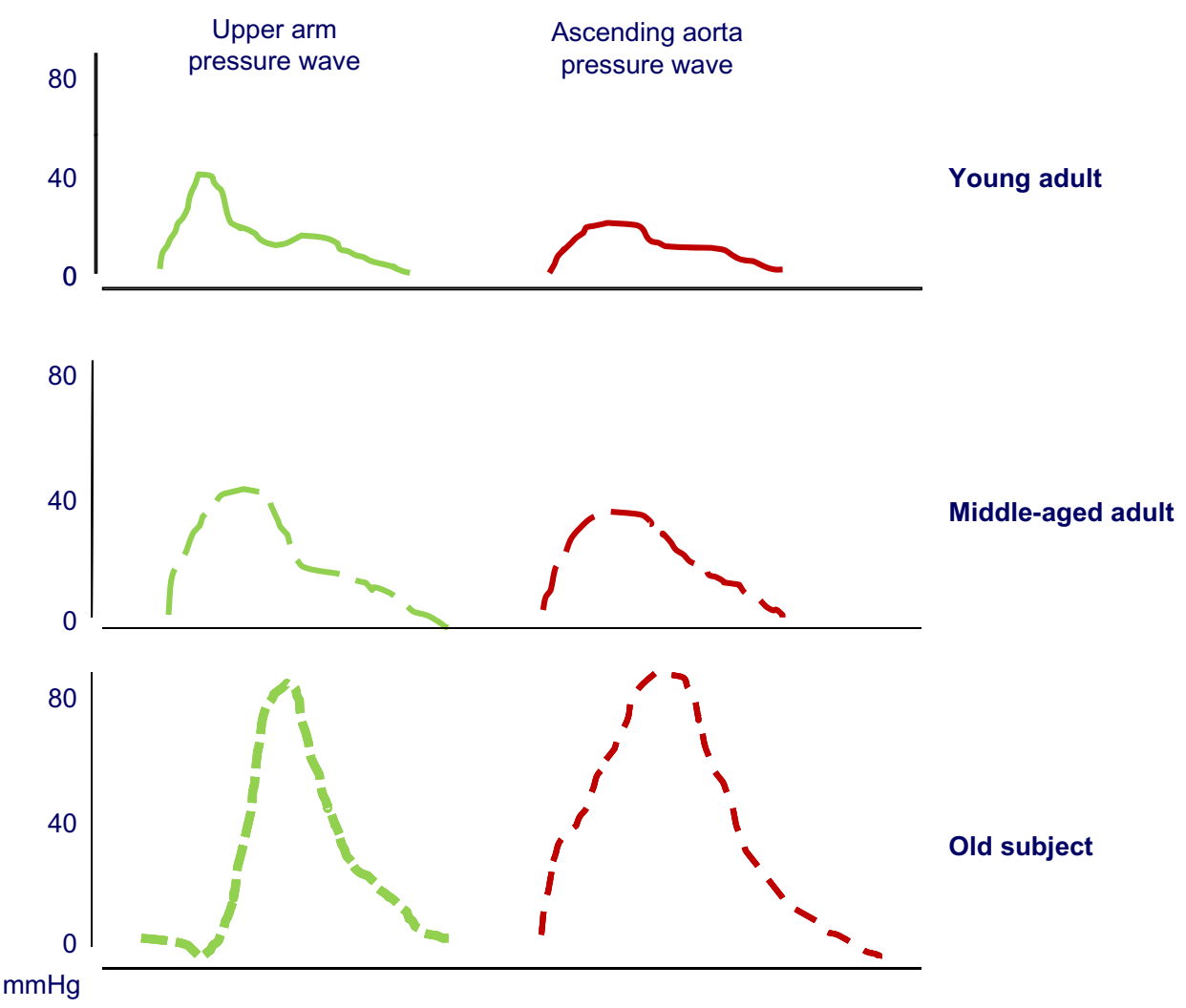

Figure I Change of peripheral (upper arm) and central (ascending aorta) pressure wave form with age.

Notes: The pulse pressure difference between the young and the old subject increases more in the aorta than in the peripheral artery. 
of adverse events in both general population samples and in large groups of patients with several CV risk factors or diseases. In 2010, Vlachopoulos et $\mathrm{al}^{9}$ published a meta-analysis of eleven longitudinal studies of 5,648 subjects and showed a $9 \%$ increase in the risk of a $\mathrm{CV}$ event for every $10 \mathrm{mmHg}$ increase in central BP. ${ }^{9}$ In the same review, an increase of central pulse pressure by $10 \mathrm{mmHg}$ was associated with a $14 \%$ increase in the risk of a CV event, and an increase in augmentation index of $10 \%$ was associated with a $32 \%$ increase in the risk of a CV event and a $38 \%$ increased risk of death from all causes.

Five papers ${ }^{19,22-25}$ have looked at the predictive power of central pressures versus that of peripheral pressures, and the meta-analysis ${ }^{9}$ has shown a trend for central pulse pressure (PP) to be more predictive than peripheral PP $(P=0.057)$, while no difference for SBP was observed.

\section{Noninvasive measurement of central aortic pressure}

Invasive measurement of central BP cannot be routinely applied in asymptomatic patients; therefore, we must rely on noninvasive methods. The noninvasive measurement of central aortic pressure relates to the analysis of an arterial waveform by different methods, and usually is calibrated with brachial BP (Table 1).

The methods described for the arterial waveform analysis at the level of the carotid or radial arteries are applanation tonometry and oscillometric methods using a standard brachial BP cuff. Tonometry of the carotid or radial artery is performed directly with a hand-held piezoelectric probe or a tonometer, requiring some skill and reasonable training for good quality pressure waveform recordings. More recently, new devices have been developed allowing an operator-independent recording of the arterial pressure waveform, based on applanation tonometry (using the Omron HEM-9000AI, Vicorder ${ }^{\circledR}$, or Complior) and oscillometry (using the Arteriograph ${ }^{\mathrm{TM}}$; TensioMed Kft, Budapest, Hungary).

When using radial tonometry, brachial BP is measured using a conventional cuff-based device before proceeding with tonometry and while the patient is seated or supine, and a minimal amplification between brachial and radial arteries is assumed. When the cuff-based oscillometric method is performed (for example, with the Arteriograph ${ }^{\mathrm{TM}}$ or the Mobil-O-Graph [IEM GmbH, Stolberg, Germany]), the brachial BP is measured simultaneously to the brachial arterial waveform acquisition, and in this case the brachial-radial amplification may be overcome.

For the analysis of the arterial (carotid, radial, or brachial) waveform, three different approaches have been proposed: 1) the use of a generalized transfer function; 2) the derivation of the inflection point on the descending slope of the systolic pressure wave, called the secondary systolic wave (SBP2) method; and 3) the N-point moving average (NPMA) method. The oscillometric method with a generalized transfer function, and the NPMA method allow for 24-hour central systolic pressure monitoring. ${ }^{26}$

Several generalized transfer functions describing the relationship between central and brachial BP in the frequency domain have been developed to derive aortic waveform from the peripheral artery waveform. The peak of the aortic wave represents the central aortic systolic SBP, and the foot of the wave represents the central aortic diastolic BP (DBP). From the aortic wave, the augmented pressure (ie, the difference between central SBP and the peak of the outgoing pressure wave [inflection point]) may be calculated., ${ }^{7,27-30}$

A transfer function encodes the alterations introduced by a system (the arterial tree) on the original signal

Table I Validation studies

\begin{tabular}{|c|c|c|c|}
\hline Study & Subjects & Device & Results \\
\hline Weiss et $\mathrm{al}^{30}$ & $\begin{array}{l}34 \text { normotensives } \\
56 \text { hypertensive }\end{array}$ & $\begin{array}{l}\text { Mobil-O-Graph (IEM GmbH, } \\
\text { Stolberg, Germany) }\end{array}$ & $\begin{array}{l}\text { Comparison of central BP measurement vs } \\
\text { radial tonometry (SphygmoCor) }\end{array}$ \\
\hline Luzardo et al $^{64}$ & $\begin{array}{l}35 \text { normotensives at rest } \\
83 \text { normotensives at rest and during daytime }\end{array}$ & Mobil-O-Graph & $\begin{array}{l}\text { Comparison of central BP measurement vs } \\
\text { radial tonometry (SphygmoCor) }\end{array}$ \\
\hline Weber et $\mathrm{al}^{61}$ & 30 subjects & $\begin{array}{l}\text { Oscillometric/ARCSolver algorithm } \\
\text { Tonometry/transfer function }\end{array}$ & Validation vs invasive measurement \\
\hline Williams et $\mathrm{al}^{46}$ & $\begin{array}{l}\text { I5 subjects for the invasive study } \\
217 \text { volunteers for the comparison study }\end{array}$ & $\begin{array}{l}\text { A-Pulse tonometer ( } \mathrm{N} \text {-point moving } \\
\text { average) } \\
\text { SphygmoCor (generalized transfer } \\
\text { function) }\end{array}$ & $\begin{array}{l}\text { Validation vs invasive measurement } \\
\text { Comparison of central systolic BP } \\
\text { measurement with A-Pulse and } \\
\text { SphygmoCor }\end{array}$ \\
\hline Ott et $\mathrm{al}^{49}$ & 52 patients & $\begin{array}{l}\text { BPro }{ }^{\circledR} \text { device with A-Pulse } \\
\text { SphygmoCor }\end{array}$ & Validation vs invasive measurement \\
\hline
\end{tabular}

Abbreviations: BP, blood pressure; vs, versus. 
(the radial waveform), which generates the output (the aortic waveform), and assumes that the properties of the upper limb arteries are virtually identical between individuals. Most of the validation studies to date have been carried out in men undergoing diagnostic cardiac catheterization, ${ }^{27,31-36}$ and the accuracy of the transfer function in women, ${ }^{37}$ in individuals without coronary disease, ${ }^{38}$ after exercise,${ }^{39}$ or in supine rather than sitting positions ${ }^{40}$ has been a matter of debate.

A recent meta-analysis ${ }^{41}$ was performed in order to systematically examine the accuracy of non-invasive methods based on applanation tonometry proposed to estimate central BP. The meta-analysis examined 22 available studies (including 857 subjects and 1,167 measurements). When the acquired arterial pressure waveforms were calibrated to match invasive measurements of aortic mean BP and DBP, the errors of estimated central BP were small, with a mean and standard deviation of difference of $-1.1 \pm 4.1 \mathrm{mmHg}(95 \%$ limits of agreement; -9.1 to $-6.9 \mathrm{mmHg}$ ) for central SBP; $-0.5 \pm 2.1 \mathrm{mmHg}(95 \%$ limits of agreement; -4.6 to $-3.6 \mathrm{mmHg}$ ) for central DBP; and $-0.8 \pm 5.1$ $\mathrm{mmHg}$ (95\% limits of agreement; -10.8 to $-9.2 \mathrm{mmHg}$ ) for central PP. In contrast, when acquired arterial pressure waveforms were calibrated to match the brachial BP measured with a sphygmomanometer, the errors were higher: $-8.2 \pm 10.3 \mathrm{mmHg}$ ( -28.4 to $12.0 \mathrm{mmHg}$ ) for central SBP; $7.6 \pm 8.7 \mathrm{mmHg}$ (-9.5 to $24.6 \mathrm{mmHg})$ for central DBP; and $-12.2 \pm 10.4 \mathrm{mmHg}(-32.5$ to $8.1 \mathrm{mmHg}$ ) for central pulse pressure. The results of this meta-analysis suggest the need for improvement in measurement accuracy of central BP when cuff BP is used to calibrate the peripheral waveforms.

The identification of the inflection point, termed SBP2, has been used to derive central aortic SBP. This second peak of the pressure waveform, also defined as the late systolic shoulder of the peripheral pressure waveform, was shown to approximate to central SBP. ${ }^{42-44}$ Mean BP may be calculated from systolic and diastolic brachial BP, and as it is assumed that peripheral mean BP is substantially similar to the mean BP in the aortic root, central DBP may be calculated after derivation of central SBP at the SBP2. However, the identification of the second peak of aortic pressure may be not easy, especially in elderly subjects with stiff arteries or in young people with early peak systolic pressure in the absence of augmentation, thus representing an important limitation to its clinical use. The correct identification of the second peak may also be influenced by the acquisition of the arterial pressure waveform. ${ }^{45}$

Finally, the capability of the NPMA method to estimate central SBP was demonstrated. ${ }^{46}$ The NPMA is a mathematical low-pass filter that can smooth the high-frequency components, resulting primarily from arterial wave reflections of noninvasively acquired radial pressure waveforms, and thereby reveals the underlying peak of the central aortic pressure waveform, or central SBP. Each single point in the signal is summed up with its neighbors and divided by the number of considered data points. The more data points are taken in the original formula, the smoother is the signal. Therefore, the common denominator of the filter is critical and is related to sample frequency; the NPMA method with a common denominator of 4 (a quarter of the acquisition sampling frequency) has been shown to define central SBP accurately. ${ }^{46}$

Very recently, the application of the NPMA method to a cuff-based technique, introduced into current oscillometric BP monitors, was developed and validated. ${ }^{47,49}$ A disadvantage of this method is represented by the lack of information of central pressure waveform because of its filtering characteristics, which remove all pulse wave features $>4 \mathrm{~Hz}$, a frequency range primarily represented by wave reflections.

Despite the widespread use of these techniques, there are still some methodological problems. For example, some difference was observed in a study comparing central SBP measured with the SphygmoCor device and with the Omron, possibly due to the use of a different algorithm. ${ }^{50,51}$ In fact, with any of these methods, the central BP value is calibrated on the brachial BP measured in the same session, and may introduce a systematic error. This point was clearly addressed by Soender et al, ${ }^{52}$ who examined if different calibrations with brachial SBP and DBP, or with DBP and calculated mean BP, had an impact on estimates of central BPs using the SphygmoCor device. The results of the study have shown that calibration with DBP and mean arterial pressure produces higher estimates of central BPs than recommended, and most importantly, has an impact on the interpretation of clinical results. ${ }^{52}$

Considering the problems relative to feasibility and reproducibility of different methods proposed for central $\mathrm{BP}$ evaluation, the issue of reference values for central BP seems to be of one of great importance. A large reference value project for central pressures, involving more than 85,000 individuals, has been conducted in Europe, and will provide normal reference values. ${ }^{53}$ The results provided by this project will add useful information to a recent study performed in Taiwan, deriving central BP thresholds by their predictive value of $\mathrm{CV}$ outcomes (2,501 individuals with median follow-up of 10 years). ${ }^{54}$

\section{Ambulatory central BP monitoring}

Most studies on central BP have collected measurements in resting conditions, comparing central and brachial $\mathrm{BP}$ 
measurements at rest. These studies have shown that central BP has a greater prognostic significance as compared with office BP. However, when central BP was compared to 24-hour mean BP in predicting the risk for CV events, both measurements had similar effect. . $^{21,55,56}$

The clinical importance of 24-hour ambulatory BP measurement has been recently underlined by the European Society of Hypertension (ESH) recommendations for the use of 24-hour ambulatory BP devices. ${ }^{57}$ The use of 24-hour ambulatory BP monitoring (ABPM) is not only related to the detection of hypertension, but also to the identification of circadian BP profiles and BP variability, both in untreated subjects and during antihypertensive treatment.

In the last 10 years, technological progress has allowed the development of some ABPM devices for the measurement of central aortic pressure or pulse wave velocity, continuously or intermittently, and a few studies have been performed, making an important step forward by evaluating 24-hour ambulatory central aortic BP (Tables 1 and 2).

Twenty-four hour central systolic pressure monitoring may be performed by the recording of the brachial artery waveform by the oscillometric method, and by using a generalized transfer function, ${ }^{26}$ or the NPMA method for central BP estimation. ${ }^{58}$ One of the first studies aimed to assess 24-hour ambulatory central BP was conducted with the Mobil-OGraph, an automated self-measurement 24-hour BP monitoring device. The device offers fully automated programmable oscillometric BP obtained at the upper arm, and has been validated by the BHS (British Hypertension Society) ${ }^{59}$ and the ESH. ${ }^{60}$ This device was implemented with a novel method, ARCSolver (Austrian Institute of Technology, Vienna, Austria), and assessed for the measurement of derived arterial and central hemodynamic parameters in invasive ${ }^{61,62}$ and noninvasive studies. ${ }^{63}$ The central BP measurements obtained with the device have also been compared with those recorded with the SphygmoCor device, which is widely known as the most commonly used approach to noninvasive assessment of aortic BP ${ }^{30}$ The comparison of BP values measured by the two devices showed a statistically significant linear correlation $(r=0.91)$, and Bland-Altman analysis showed a mean difference between replicate measurements of $1.89 \mathrm{mmHg}^{30}$

In a study by Luzardo et al, ${ }^{64} 115$ volunteers aged 18 to 64 years were enrolled in their working place, and therefore were considered as representative of a general population sample. All subjects underwent arterial tonometry and oscillometric evaluation of central BP at rest, and 83 subjects were further evaluated with daytime ambulatory monitoring. The results of the study have shown that central SBP values and central augmentation index, assessed by Mobil-O-Graph 24-hour pulse wave analysis monitor and by SphygmoCor, were similar, while the use of the oscillometric technique yielded to higher DBP and, as a consequence, lower PP, suggesting that ambulatory assessment of central hemodynamic variables is feasible. Protogerou et $\mathrm{al}^{65}$ investigated further the feasibility and reproducibility of 24-hour aortic ABPM in 30 consecutive subjects, performing a 24-hour ABPM twice, one week apart for each subject. The data have shown no differences between the two types of ambulatory monitoring for all measures of central BP; the intra-class correlation coefficient was 0.80 and 0.92 for SBP and DBP, respectively, indicating an acceptable reproducibility. ${ }^{65}$ More recently, Jankowski et $\mathrm{al}^{26}$ assessed the circadian central BP profile with the simultaneously measured peripheral BP in addition to central SBP short-term variability, and 24-hour systolic pressure amplification profile in 50 hypertensive subjects and 50 normotensive subjects. During both daytime and night, peripheral pressure was higher than central BP, with a lower nocturnal decline in central BP as compared with peripheral BP. Systolic pressure amplification was similar in normotensives and in hypertensive patients, and in both groups it was

Table 2 Clinical studies using 24-hour central BP recordings

\begin{tabular}{|c|c|c|c|}
\hline Study & Subjects & Device & Aim of the study \\
\hline Jankowski et $\mathrm{al}^{26}$ & $\begin{array}{l}50 \text { normotensives } \\
50 \text { hypertensives }\end{array}$ & BPro $^{\circledR}$ (HealthSTATS, Singapore) & Measurements of 24-hour peripheral and central pressure \\
\hline Theilade et al $^{69}$ & $\begin{array}{l}629 \text { patients with diabetes type I } \\
86 \text { controls }\end{array}$ & BPro $^{\circledR}$ & $\begin{array}{l}\text { Assessment of the correlation between central BP and } \\
\text { diabetes-related complications }\end{array}$ \\
\hline Freercks et $\mathrm{al}^{70}$ & 74 prevalent dialysis patients & BPro $^{\circledR}$ & Correlation of central BP values with vascular calcification \\
\hline Protogerou et $\mathrm{al}^{65}$ & $\begin{array}{l}30 \text { hypertensive consecutive } \\
\text { subjects }\end{array}$ & $\begin{array}{l}\text { Mobil-O-Graph (IEM GmbH, } \\
\text { Stolberg, Germany) }\end{array}$ & Assessment of reproducibility of 24-hour BP recordings \\
\hline Williams et $\mathrm{al}^{58}$ & I7I patients (AmCAP) study & BPro $^{\circledR}$ & Effect of antihypertensive treatment \\
\hline Protogerou et $\mathrm{al}^{71}$ & $\begin{array}{l}229(75 \% \text { hypertensive }) \\
\text { consecutive subjects }\end{array}$ & Mobil-O-Graph & $\begin{array}{l}\text { Correlation between LVH, and central and peripheral } \\
\text { 24-hour BP recordings }\end{array}$ \\
\hline
\end{tabular}

Abbreviations: BP, blood pressure; AmCAP, the Ambulatory Central Aortic Pressure study; LVH, left ventricular hypertrophy. 
significantly lower during the night than during the day. In addition, a significant correlation was found between the fall in systolic pressure amplification during nighttime and the day-night difference in heart rate $(r=0.70 ; P<0.001)$.

Similar results were reported by the measurement of 24-hour ambulatory central BP within a randomized controlled trial ASSERTIVE (AliSkiren Study of profound antihypERtensive efficacy in hyperTensIVE patients). ${ }^{58}$ Twenty-fourhour ambulatory brachial and central BP measurements were acquired using a tonometer mounted into the articulating strap of a wristwatch-like device (BPro ${ }^{\circledR}$; HealthSTATS, Singapore) worn by 171 participants in the study. A typical circadian pattern was observed for both brachial and central BP, with lower pressures at night, although smaller reductions in central relative to brachial pressure, and decreased pulse pressure amplification were shown during the night. In this study, these differences remained significant after adjusting for heart rate and for daytime and nighttime BP. Antihypertensive treatment with either aliskiren or telmisartan did not affect the different diurnal patterns of brachial and central pressure, but reduced both day and night BP values to a lower BP level. ${ }^{58}$ All these data indicate that nighttime central BP is higher than brachial pressure and warrants further investigation.

Another interesting aspect that has been only partially addressed is the relationship between 24 hour ambulatory central versus brachial BP and target organ damage. Ambulatory peripheral BP is highly related to the development and progression of target organ damage. At the same time, it has been shown that central BP may exert a stronger influence on LV mass increase, on the impairment of LV systolic and diastolic dysfunction, myocardial ischemia, but also carotid intima-media thickening and plaque, ${ }^{66}$ or retinal arterioles' wall-to-lumen ratio. ${ }^{20,21}$

The BP Guide study aimed to obtain the best BP control in about 300 hypertensive patients by giving treatment guided by best-practice usual care (ie, using office, home, and 24-hour ambulatory BP) or, in addition, by central BP intervention as measured by the SphygmoCor; ${ }^{67}$ the results, recently published, ${ }^{68}$ have shown that hypertension management with central BP may result in the use of less medication and no adverse effects on LV mass, aortic stiffness, or quality of life.

In a large study including 715 individuals, three groups of patients with diabetes mellitus type 1 (69 patients with diabetes duration of less than 10 years, normoalbuminuria, and not receiving antihypertensive treatment; 211 with longstanding diabetes and normoalbuminuria; 163 with microalbuminuria; and 186 with macroalbuminuria) were compared to 86 controls. ${ }^{69}$ In all subjects, 24-hour central BP and brachial BP monitoring was performed using a tonometric wrist-watch-like device $\left(\right.$ BPro $\left.^{\circledR}\right)$, and central BP values were derived using NPMA. The results showed that 24-hour mean central SBP and pulse pressure were higher in patients with diabetes type 1, previous CV disease, retinopathy, and autonomic dysfunction, and paralleled the degree of albuminuria. The correlation between BP and diabetic complications was stronger for 24-hour central BP than peripheral BP. In contrast, in a cohort of 74 African hypertensive patients with end-stage kidney disease and on dialysis treatment, the presence of coronary or aortic vascular calcification was not associated with changes in ambulatory central aortic systolic pressure ${ }^{67,70}$ Few preliminary data seem to indicate that 24-hour central SBP is more closely related to LV mass index than other measures (peripheral 24-hour BP, office central BP, and office brachial BP), as assessed by the Mobil-O-Graph and SphygmoCor devices. A study, performed in 229 individuals (75\% hypertensive patients) has recently confirmed that the 24-hour average aortic SBP was significantly better associated with left ventricular mass index than the 24-hour average brachial, office (brachial or aortic) SBP, independently of age, sex, obesity, or treatment. ${ }^{71}$ Another prospective multicenter study is currently ongoing in order to assess the relationship between LV mass and function, and central aortic BP measured throughout the 24-hour period. ${ }^{72}$

The availability of ambulatory central BP measurements will open a new field of research, and a large number of issues will be matter of interest. The prognostic importance attributed to brachial nighttime BP needs to be reassessed by the evaluation of central aortic measurements. Ambulatory central BP measurements will offer an additional important tool to mechanistic and clinical studies on BP variability, and obviously will be a tool for investigating the effect of antihypertensive treatment. Ultimately, it will be necessary to evaluate the prognostic value of 24-hour ambulatory central pressure: reasonably, it can be hypothesized that 24-hour central BP is superior, in this regard, to brachial 24-hour BP.

\section{Conclusion}

Taking into account all the available evidence, it is premature to recommend the use of ambulatory central BP in the place of peripheral BP in everyday clinical practice. The accuracy and reproducibility of all available devices need to be evaluated, with simultaneous recording of peripheral and central BP, and the cost of devices should be affordable. The prognostic role for $\mathrm{CV}$ events of central pressure measurements as compared with brachial pressure measurements 
should be demonstrated in the general population and with different subsets of patients.

\section{Disclosure}

The authors report no conflicts of interest in this work.

\section{References}

1. Riva-Rocci S, Zanchetti A, Mancia G. A new sphygmomanometer. Sphygmomanometric technique. J Hypertens. 1996;14(1):1-12.

2. O'Rourke MF, Adji A. Basis for use of central blood pressure measurement in office clinical practice. J Am Soc Hypertens. 2008;2(1): 28-38.

3. Wilkinson IB, McEniery CM, Cockcroft JR. Central blood pressure estimation for the masses moves a step closer. J Hum Hypertens. 2010;24(8):495-497.

4. Wilkinson IB, McEniery CM, Cockcroft JR. Pulse waveform analysis and arterial stiffness: realism can replace evangelism and scepticism. J Hypertens. 2005;23(1):213-214.

5. Williams B. Pulse wave analysis and hypertension: evangelism versus scepticism. J Hypertens. 2004;22(3):447-449.

6. O'Rourke MF, Kim M, Adji A, Nichols WW, Avolio A. Use of arterial transfer function for the derivation of aortic waveform characteristics. J Hypertens. 2004;22(2):431-432.

7. Karamanoglu M, O'Rourke MF, Avolio AP, Kelly RP. An analysis of the relationship between central aortic and peripheral upper limb pressure waves in man. Eur Heart J. 1993;14(2):160-167.

8. Chirinos JA, Zambrano JP, Chakko S, et al. Aortic pressure augmentation predicts adverse cardiovascular events in patients with established coronary artery disease. Hypertension. 2005;45(5):980-985.

9. Vlachopoulos C, Aznaouridis K, Stefanadis C. Prediction of cardiovascular events and all-cause mortality with arterial stiffness: a systematic review and meta-analysis. J Am Coll Cardiol. 2010;55(13): 1318-1327.

10. Sharman JE, Laurent S. Central blood pressure in the management of hypertension: soon reaching the goal? J Hum Hypertens. 2013;27(7): 405-411.

11. O’Rourke M, Safar M. Relationship between aortic stiffening and microvascular disease in brain and kidney: cause and logic of therapy. Hypertension. 2005;46:200-204.

12. Roman MJ. Association of central and peripheral pulse pressure with intermediate cardiovascular phenotypes. J Hypertens. 2012;30(4): $834-835$.

13. Roman MJ, Devereux RB. Association of central and peripheral blood pressures with intermediate cardiovascular phenotypes. Hypertension. 2014;63(6):1148-1153.

14. Roman MJ, Okin PM, Kizer JR, Lee ET, Howard BV, Devereux RB. Relations of central and brachial blood pressure to left ventricular hypertrophy and geometry: the Strong Heart Study. J Hypertens. 2010;28(2):384-388.

15. Laurent S, Briet M, Boutouyrie P. Large and small artery cross-talk and recent morbidity-mortality trials in hypertension. Hypertension. 2009;54(2):388-392.

16. Roman MJ. Association of central and peripheral pulse pressure with intermediate cardiovascular phenotypes. J Hypertens. 2012;30(4): 834-835.

17. Ostergren J, Poulter NR, Sever PS, et al. The Anglo-Scandinavian Cardiac Outcomes Trial: blood pressure-lowering limb: effects in patients with type II diabetes. J Hypertens. 2008;26(11):2103-2111.

18. Norton GR, Majane OH, Maseko MJ, et al. Brachial blood pressureindependent relations between radial late systolic shoulder-derived aortic pressures and target organ changes. Hypertension. 2012;59(4): 885-892.

19. Roman MJ, Devereux RB, Kizer JR, et al. Central pressure more strongly relates to vascular disease and outcome than does brachial pressure: the Strong Heart Study. Hypertension. 2007;50(1):197-203.
20. Ott C, Raff U, Harazny JM, Michelson G, Schmieder RE. Central pulse pressure is an independent determinant of vascular remodeling in the retinal circulation. Hypertension. 2013;61(6):1340-1345.

21. Salvetti M, Agabiti Rosei C, Paini A, et al. Relationship of wall-to-lumen ratio of retinal arterioles with clinic and 24-hour blood pressure. Hypertension. 2014;63(5):1110-1115.

22. Dart AM, Gatzka CD, Kingwell BA, et al. Brachial blood pressure but not carotid arterial waveforms predict cardiovascular events in elderly female hypertensives. Hypertension. 2006;47(4):785-790.

23. Pini R, Cavallini MC, Palmieri V, et al. Central but not brachial blood pressure predicts cardiovascular events in an unselected geriatric population: the ICARe Dicomano Study. J Am Coll Cardiol. 2008;51(25):2432-2439.

24. Safar ME, Blacher J, Pannier B, et al. Central pulse pressure and mortality in end-stage renal disease. Hypertension. 2002;39(3):735-738.

25. Jankowski P, Kawecka-Jaszcz K, Czarnecka D, et al. Pulsatile but not steady component of blood pressure predicts cardiovascular events in coronary patients. Hypertension. 2008;51(4):848-855.

26. Jankowski P, Bednarek A, Olszanecka A, Windak A, KaweckaJaszcz K, Czarnecka D. Twenty-four-hour profile of central blood pressure and central-to-peripheral systolic pressure amplification. Am J Hypertens. 2013;26(1):27-33.

27. Chen $\mathrm{CH}$, Nevo E, Fetics B, et al. Estimation of central aortic pressure waveform by mathematical transformation of radial tonometry pressure. Validation of generalized transfer function. Circulation. 1997;95(7): 1827-1836.

28. Fetics B, Nevo E, Chen CH, Kass DA. Parametric model derivation of transfer function for noninvasive estimation of aortic pressure by radial tonometry. IEEE Trans Biomed Eng. 1999;46(6):698-706.

29. Hope SA, Tay DB, Meredith IT, Cameron JD. Use of arterial transfer functions for the derivation of aortic waveform characteristics. J Hypertens. 2003;21(7):1299-1305.

30. Weiss W, Gohlisch C, Harsch-Gladisch C, Tölle M, Zidek W, van der Giet M. Oscillometric estimation of central blood pressure: validation of the Mobil-O-Graph in comparison with the SphygmoCor device. Blood Press Monit. 2012;17(3):128-131.

31. Hope SA, Meredith IT, Cameron JD. Arterial transfer functions and the reconstruction of central aortic waveforms: myths, controversies and misconceptions. J Hypertens. 2008;26(1):4-7.

32. Karamanoglu M, Feneley MP. Derivation of the ascending aorticcarotid pressure transfer function with an arterial model. Am J Physiol. 1996;271(6 Pt 2):H2399-H2404.

33. Hope SA, Meredith IT, Cameron JD. Effect of non-invasive calibration of radial waveforms on error in transfer-function-derived central aortic waveform characteristics. Clin Sci (Lond). 2004;107(2):205-211.

34. Segers P, Mahieu D, Kips J, Van Bortel LM. The use of a generalized transfer function: different processing, different results! J Hypertens. 2007;25(9):1783-1787.

35. Papaioannou TG, Protogerou A, Stefanadis C. Comparison between Mobil-O-Graph and the SphygmoCor device for central systolic blood pressure estimation: consensus is required for 'validation protocols'. Blood Press Monit. 2012;17(6):259-260.

36. Pauca AL, O'Rourke MF, Kon ND. Prospective evaluation of a method for estimating ascending aortic pressure from the radial artery pressure waveform. Hypertension. 2001;38(4):932-937.

37. Hope SA, Tay DB, Meredith IT, Cameron JD. Comparison of generalized and gender-specific transfer functions for the derivation of aortic waveforms. Am J Physiol Heart Circ Physiol. 2002;283(3): H1150-H1156.

38. Segers $P$, Carlier S, Pasquet A, et al. Individualizing the aorto-radial pressure transfer function: feasibility of a model-based approach. Am J Physiol Heart Circ Physiol. 2000;279(2):H542-H549.

39. Payne RA, Teh CH, Webb DJ, Maxwell SR. A generalized arterial transfer function derived at rest underestimates augmentation of central pressure after exercise. J Hypertens. 2007;25(11):2266-2272.

40. Vrachatis D, Papaioannou TG, Konstantopoulou A, et al. Effect of supine versus sitting position on noninvasive assessment of aortic pressure waveform: a randomized cross-over study. J Hum Hypertens. 2014;28(4):236-241. 
41. Cheng HM, Lang D, Tufanaru C, Pearson A. Measurement accuracy of non-invasively obtained central blood pressure by applanation tonometry: a systematic review and meta-analysis. Int J Cardiol. 2013;167(5):1867-1876.

42. Takazawa K, Tanaka N, Takeda K, Kurosu F, Ibukiyama C. Underestimation of vasodilator effects of nitroglycerin by upper limb blood pressure. Hypertension. 1995;26(3):520-523.

43. Pauca AL, Kon ND, O'Rourke MF. The second peak of the radial artery pressure wave represents aortic systolic pressure in hypertensive and elderly patients. Br J Anaesth. 2004;92(5):651-657.

44. Millasseau SC, Patel SJ, Redwood SR, Ritter JM, Chowienczyk PJ. Pressure wave reflection assessed from the peripheral pulse: is a transfer function necessary? Hypertension. 2003;41(5):1016-1020.

45. Agnoletti D, Millasseau S, Topouchian J, Zhang Y, Safar ME, Blacher J. [Pressure wave shape comparison between two non-invasive tonometric devices]. Ann Cardiol Angeiol (Paris). 2013;62(3):193-199. French.

46. Williams B, Lacy PS, Yan P, Hwee CN, Liang C, Ting CM. Development and validation of a novel method to derive central aortic systolic pressure from the radial pressure waveform using an n-point moving average method. J Am Coll Cardiol. 2011;57(8):951-961.

47. Cheng HM, Sung SH, Shih YT, Chuang SY, Yu WC, Chen CH. Measurement accuracy of a stand-alone oscillometric central blood pressure monitor: a validation report for Microlife WatchBP Office Central. Am J Hypertens. 2013;26(1):42-50.

48. Shih YT, Cheng HM, Sung SH, Hu WC, Chen CH. Application of the $\mathrm{N}$-point moving average method for brachial pressure waveform-derived estimation of central aortic systolic. Hypertension. 2014;63:865-870.

49. Ott C, Haetinger S, Schneider MP, Pauschinger M, Schmieder RE. Comparison of two noninvasive devices for measurement of central systolic blood pressure with invasive measurement during cardiac catheterization. J Clin Hypertens (Greenwich). 2012;14(9):575-579.

50. Mahieu D, Kips J, Rietzschel ER, et al. Noninvasive assessment of central and peripheral arterial pressure (waveforms): implications of calibration methods. J Hypertens. 2010;28(2):300-305.

51. Kips JG, Schutte AE, Vermeersch SJ, et al. Comparison of central pressure estimates obtained from SphygmoCor, Omron HEM-9000AI and carotid applanation tonometry. J Hypertens. 2011;29(6):1115-1120.

52. Soender TK, Van Bortel LM, Møller JE, Lambrechtsen J, Hangaard J, Egstrup K. Impact of calibration on estimates of central blood pressures. J Hum Hypertens. 2012;26(12):706-710.

53. Weber T, Wassertheurer S, Hametner B, et al. Letter to the Editor: reference values for central blood pressure. $\mathrm{J} \mathrm{Am} \mathrm{Coll} \mathrm{Cardiol.}$ 2014;63(21):2299-2300.

54. Cheng HM, Chuang SY, Sung SH, et al. Derivation and validation of diagnostic thresholds for central blood pressure measurements based on longterm cardiovascular risks. J Am Coll Cardiol. 2013;62(19):1780-1787.

55. Kallem RR, Meyers KE, Cucchiara AJ, Sawinski DL, Townsend RR. Blood pressure variability of two ambulatory blood pressure monitors. Blood Press Monit. 2014;19(2):98-102.

56. Huang CM, Wang KL, Cheng HM, et al. Central versus ambulatory blood pressure in the prediction of all-cause and cardiovascular mortalities. J Hypertens. 2011;29(3):454-459.

57. O'Brien E, Parati G, Stergiou G, et al; European Society of Hypertension Working Group on Blood Pressure Monitoring. European society of hypertension position paper on ambulatory blood pressure monitoring. J Hypertens. 2013;31(9):1731-1768.
58. Williams B, Lacy PS, Baschiera F, Brunel P, Düsing R. Novel description of the 24-hour circadian rhythms of brachial versus central aortic blood pressure and the impact of blood pressure treatment in a randomized controlled clinical trial: The Ambulatory Central Aortic Pressure (AmCAP) Study. Hypertension. 2013;61(6):1168-1176.

59. Wei W, Tölle M, Zidek W, van der Giet M. Validation of the mobil-OGraph: 24 h-blood pressure measurement device. Blood Press Monit. 2010;15(4):225-228.

60. Franssen PM, Imholz BP. Evaluation of the Mobil-O-Graph new generation ABPM device using the ESH criteria. Blood Press Monit. 2010;15(4):229-231.

61. Weber T, Wassertheurer S, Rammer M, et al. Validation of a brachial cuff-based method for estimating central systolic blood pressure. Hypertension. 2011;58(5):825-832.

62. Wassertheurer S, Kropf J, Weber T, et al. A new oscillometric method for pulse wave analysis: comparison with a common tonometric method. J Hum Hypertens. 2010;24(8):498-504.

63. Nunan D, Wassertheurer S, Lasserson D, et al. Assessment of central haemomodynamics from a brachial cuff in a community setting. $B M C$ Cardiovasc Disord. 2012;12:48.

64. Luzardo L, Lujambio I, Sottolano M, et al. 24-h ambulatory recording of aortic pulse wave velocity and central systolic augmentation: a feasibility study. Hypertens Res. 2012;35(10):980-987.

65. Protogerou AD, Argyris A, Nasothimiou E, et al. Feasibility and reproducibility of noninvasive 24-h ambulatory aortic blood pressure monitoring with a brachial cuff-based oscillometric device. Am J Hypertens. 2012;25(8):876-882.

66. McEniery CM, Cockcroft JR, Roman MJ, Franklin SS, Wilkinson IB. Central blood pressure: current evidence and clinical importance. Eur Heart J. 2014;35(26):1719-1725.

67. Sharman JE, Marwick TH, Abhayaratna WP, Stowasser M. Rationale and design of a randomized study to determine the value of central Blood Pressure for GUIDing managEment of hypertension: the BP GUIDE study. Am Heart J. 2012;163(5):761-767.

68. Sharman JE, Marwick TH, Gilroy D, Otahal P, Abhayaratna WP, Stowasser M; Value of Central Blood Pressure for GUIDing ManagEment of Hypertension Study Investigators. Randomized trial of guiding hypertension management using central aortic blood pressure compared with best-practice care: principal findings of the BP GUIDE study. Hypertension. 2013;62(6):1138-1145.

69. Theilade S, Lajer M, Hansen TW, et al. 24-hour central aortic systolic pressure and 24-hour central pulse pressure are related to diabetic complications in type 1 diabetes - a cross-sectional study. Cardiovasc Diabetol. 2013;12:122.

70. Freercks RJ, Swanepool CR, Turest-Swartz KL, et al. Vascular calcification is not associated with increased ambulatory central aortic systolic pressure in prevalent dialysis patients. Cardiovasc J Afr. 2014;25(1): 4-8.

71. Protogerou AD, Argyris AA, Papaioannou TG, et al. Left-ventricular hypertrophy is associated better with 24 -h aortic pressure than 24-h brachial pressure in hypertensive patients: the SAFAR study. J Hypertens. 2014;32(9):1805-1814.

72. Weber T, McEniery C, Wilkinson I, et al. Relationship between $24 \mathrm{~h}$ ambulatory central blood pressure and left ventricular mass - Rationale and design of a prospective multicenter study. Artery Research. 2012;6(2):103-108.

Journal of Vascular Diagnostics

\section{Publish your work in this journal}

Journal of Vascular Diagnostics is an international, peer-reviewed journal of diagnostics, focusing on non invasive vascular investigation methods involved in the evaluation of vascular diseases. The journal is committed to the rapid publication in the fields of vascular diseases. Original research, review, case reports, expert opinion and commentaries

are all considered for publication. The manuscript management system is completely online and includes a very quick and fair peer-review system, which is all easy to use. Visit http://www.dovepress.com/testimonials.php to read real quotes from published authors.

\section{Dovepress}

